\title{
Patch Antenna Array for RF Energy Harvesting Systems in 2.4 GHz WLAN Frequency Band
}

\author{
Akash Kumar Gupta \\ Department of ECE \\ Raghu Institute of Technology \\ Visakhapatnam, India
}

\author{
V. Praveen, V. Swetha Sri, \\ CH. Nagavinay Kumar, B. Kishore \\ UG-Student, Department of ECE Raghu \\ Institute of Technology Visakhapatnam, \\ India
}

\begin{abstract}
In present days, technology have been emerging with significant importance mainly in wireless local area network. In this Energy harvesting is playing a key role. The RF Energy harvesting is the collection of small amounts of ambient energy to power wireless devices, Especially, radio frequency (RF) energy has interesting key attributes that make it very attractive for lowpower consumer electronics and wireless sensor networks (WSNs). Commercial RF transmitting stations like Wi-Fi, or radar signals may provide ambient RF energy. Throughout this paper, a specific emphasis is on RFEH, as a green technology that is suitable for solving power supply to WLAN node-related problems throughout difficult environments or locations that cannot be reached. For RF harvesting RF signals are extracted using antennas.in this work to extract RF energy from $2.4 \mathrm{GHz}$ an array of rectangular microstrip patch antenna is designed. $1 \times 8$ array provides gain of $15.04 \mathrm{~dB}$ with a bandwidth of $2 \%$ at WLAN frequencies
\end{abstract}

Keywords- Microstrip Antenna, Antenna Array, Gain, Effective Area, RF Energy Harvesting.

\section{INTRODUCTION}

The most wireless sensor nodes are place outdoors or even at remote locations. Thus, supplying power for these low power sensors become difficult. Even though batteries can be used at outdoors or at remote locations, periodical replacement of batteries creates hassle and difficulty in maintenance. Here Solar and RF energy harvester are good choice overcome use of batteries. As Placement of sensor may be indoor, outdoor RF harvesting is good choice. Different design challenges can be overcome by the placement of sensor may be indoor, outdoor RF energy harvesting such as efficiency, low cost and reliability. Usage of batteries cannot meet few requirements by increasing high maintenance. So, we implement an antenna array to harvest RF energy to power wireless sensor application. The designed antenna to receive RF energy, thereby it enables power to low power sensor systems.

RF energy harvesting works at different frequency bands and for ambient sources low power sensor systems can be applied. Receiver antenna captures RF waves and then they are converted into AC power, height, bandwidth, gain, return loss and input impedance are the properties that conversion efficiency depends upon. A lot of analysis is done for the study of efficiency and performance of RF energy harvesting process. The enhanced RF energy harvesting devices using patch antenna array running at the frequency band of $2.4 \mathrm{GHz}$ Wireless Local Area Network (WLAN) is described in this paper. The major motivation is usage of energy conversion and harvesting topologies that operates low power devices. It has three stages receiving antenna, energy conversion into DC output, utilization of output of output in low power applications.

\section{RADIO FREQUENCY ENERGY HARVESTING FOR MICROSTRIP ANTENNA}

Microstrip patch antenna is a metallic patch which is fabricated on a dielectric substrate. The microstrip patch antenna is layered structure of ground plane as bottom layer and dielectric substrate as medium layer and radiating patch as top layer. The radiating patch has many different geometries like rectangular, triangular, circular, polygons, or any other arbitrary shape. The most common geometry is rectangular and circular patch. Microstrip patch antenna has advantages like easy to analysis and manufacturing, low crosspolarization and directional radiation characteristics. For resonant frequency, and ease for impedance matching microstrip patch antenna is flexible. A typical patch antenna with rectangular geometry is shown in below figure 1 . The radiated patch element is placed on the top of the large rectangular ground plane. Here, substrate separates the ground plane from patch portion.

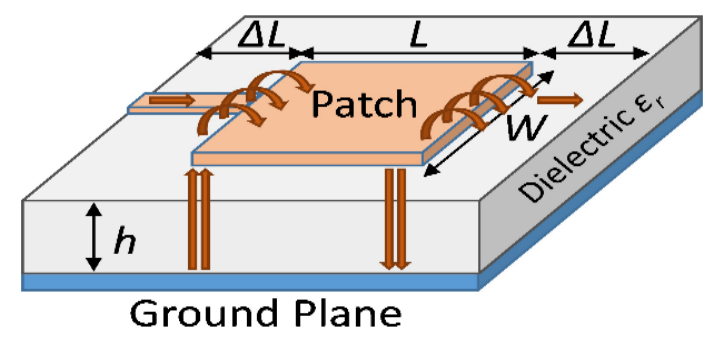

Fig. 1. Microstrip Patch Antenna

Rectangular microstrip antenna is designed for determining type of substrate used and its dielectric constant and determining the dimensions of patch like patch width(W), length (L) and the height (h) of substrate. The dielectric constant is used her is from 2.2 to 12 . For better performance of microstrip patch element, selection of the substrate is important for achieving good performance and bandwidth optimum size of patch. If a dielectric material with high value is used then it results in an increase of patch losses with a characteristic impedance. The thicker substrate will increase radiation losses as they are severely affected by surface wave propagation. By increasing patch size, the size of antenna also increases. For 
resonant frequency $\mathrm{f}$ width of the patch can be calculated by using eq. (1), while $\mathrm{c}$ is the velocity of light in free space:

$$
\begin{array}{r}
W=\frac{C}{2 f} \sqrt{\frac{2}{(\epsilon r+1)}} \\
W_{S}=\frac{\lambda}{60}
\end{array}
$$

The non-homogenous substrate and air dielectric constant can be obtained by the effective constant $\varepsilon_{r \text { eff }}$ given in eq. (2)

$$
\varepsilon_{\text {reff }}=\frac{\in r+1}{2}+\frac{\in r-1}{2} \sqrt{\left(1+\frac{12 h}{w}\right)}
$$

Length (L) can be obtained from eq.3.From eq. $4 \Delta \mathrm{L}$ is obtained as the extension of length.

$$
\begin{gathered}
L=\frac{c}{2 f \sqrt{\epsilon e f f}}-2 \Delta L, \\
L s=\frac{c}{2 f \sqrt{\epsilon e f f}}-2(L+\Delta L-W s) \\
\Delta L=0.412 h\left[\frac{\epsilon e f f+0.3}{\epsilon e f f+0.258}\right]\left[\frac{\frac{w}{h}+0.249}{\frac{w}{h}+0.8}\right]
\end{gathered}
$$

Applications for radiofrequency harvesting require high radiation characteristics, which are gain and direction. A single patch factor doesn't make them achievable. To set an antenna array, two or more antenna elements can be placed in a geometrical and electrical arrangement at the top of the same ground plane. The overall gain can be improved by providing optimal radiation characteristics of an antenna array can be used.

\section{DESIGN OF MICROSTRIP PATCH ANTENNA ARRAY FOR RF ENERGY HARVESTING}

For RMSA design the substrate material used is "Roggers RT Duroid 5880" having the value of dielectric constant as 2.2, height $(\mathrm{h})=0.8 \mathrm{~mm}$. and for patch and ground plane design PEC (Perfect Electric Conductor) material is chosen. To extract RF energy from WLAN band patch radiating frequency is chosen as $2.4 \mathrm{GHz}$.

\section{A. Single Microstrip Patch Element Design}

For maximum reception of RF energy antenna physical aperture must be large. Hence for large dimension rectangular shaped patch is chosen. The patch antenna dimensions are calculated using above formulae and tabulated below. For patch design and simulation Ansoft Ansys HFSS is used. The patch antenna is designed using calculated dimensions. To feed the antenna inset feeding method is used. Inset feed provides better impedance matching. The patch is fed with $50 \Omega$ feed line. The main challenge is to increase the bandwidth of the antenna without impacting certain properties of the antenna. For increase antenna bandwidth, many techniques like practical removal of substrates, insertion of slots in radiation patch portion of the ground plane as well as bandgap usage. A slot can be inserted in the middle of patch element or the center of patch elements radiating edge. when the slot is placed in the center of radiating edge, it forms a patch antenna array in $\mathrm{H}$ or $\mathrm{U}$ shape. To enhance the band width a rectangular cut is performed and 'H-Shaped' patch has been designed.

\section{TABLE I. MICROSTRIP PATCH ELEMENT DIMENSIONS}

\begin{tabular}{|c|c|}
\hline Effective Dielectric constant $\in$ eff & 2.11 \\
\hline Width of the Patch W & $49 \mathrm{~mm}$ \\
\hline Length of the Patch L & $39.5 \mathrm{~mm}$ \\
\hline Microstrip Line Length y0 & $11.5 \mathrm{~mm}$ \\
\hline Microstrip Line Width WL & $1 \mathrm{~mm}$ \\
\hline Insert Gap WS & $3.1 \mathrm{~mm}$ \\
\hline Width of Substrate WG & $57 \mathrm{~mm}$ \\
\hline Length of Substrate LG & $49 \mathrm{~mm}$ \\
\hline Separation distance S & 6.25 \\
\hline
\end{tabular}

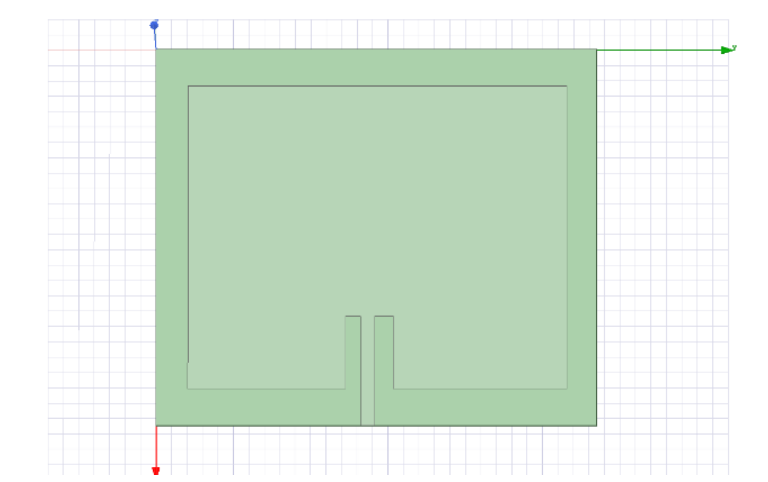

Fig. 2. Single Microstrip Patch Element Design

B. Four Elements Patch Antenna Array Design

A microstrip patch antenna performance can be enhanced using arrays of radiating elements. The antenna array is regularly spaced multiple antenna elements. The array performance is controlled using excitation amplitude, phase and separation between the elements. Four element antenna arrays are constructed using four identical RMSA separated at a $\lambda / 2$ distance. To feed the antenna array Quarter wave transformers are used. 50 $\Omega$ Microstrip Feed line is used as feedline.

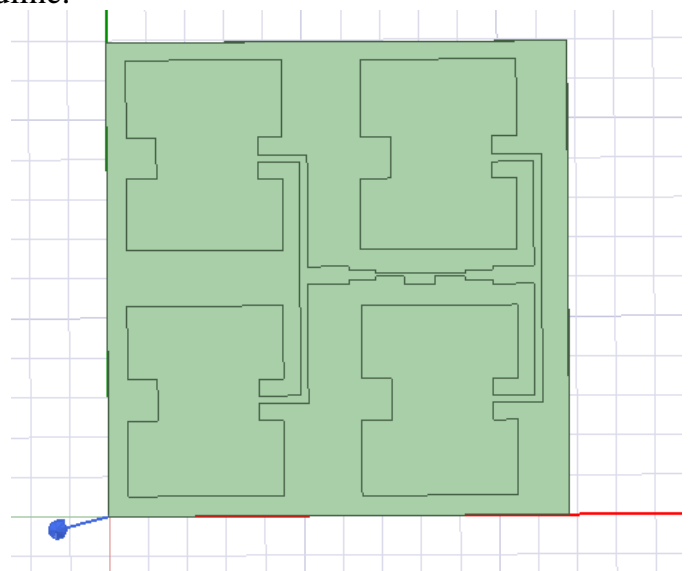

Fig. 3. Four Element Patch antenna array

C. Eight Elements Patch Antenna Array Design:

The microstrip patch antenna performance should be enhanced using arrays of radiating elements. The antenna array is regularly spaced multiple antenna elements. The array performance is controlled using excitation amplitude, phase and separation 
between the elements. Eight element antenna arrays are constructed using four identical RMSA separated at a $\lambda / 2$ distance. To feed the antenna array Quarter wave transformers are used. 50 SMicrostrip Feed line is used as feedline.

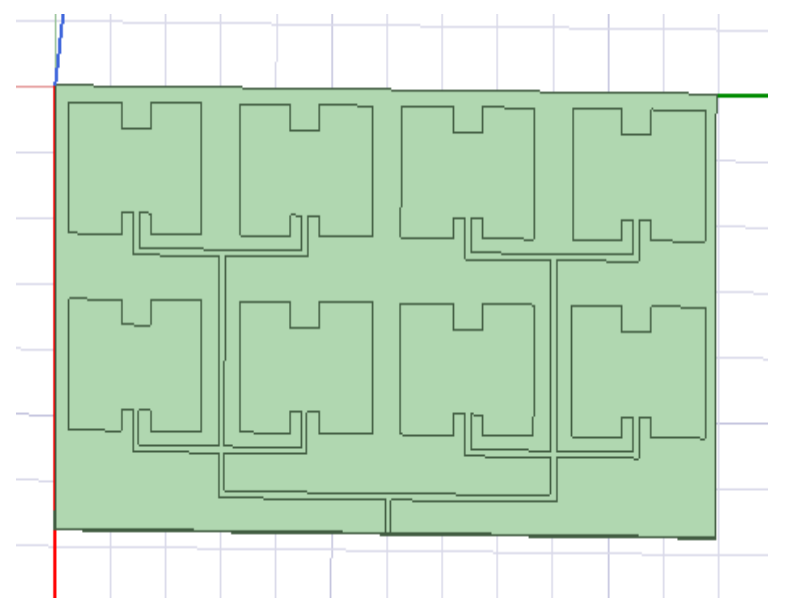

Fig. 4. Eight Element Patch antenna arrays

\section{RESULTS}

The $\mathrm{H}$ shape patch antenna array design are implemented and simulated in Ansys Electromagnetics Suite 19.2 and the results are summarized as below. The designed $\mathrm{H}$ shape patch antenna array simulated for WLAN $2.4 \mathrm{GHz}$ frequency and the following parameters are studied.

\section{A. . Return Loss:}

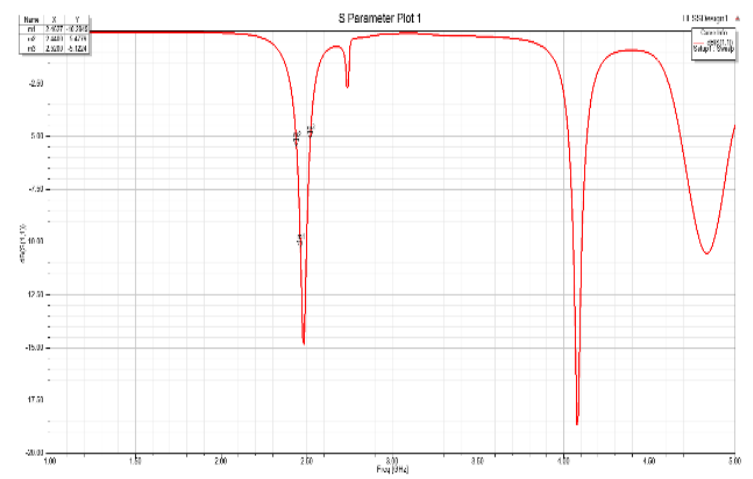

Fig. 5. Return Loss of Single Element patch antenna

The $S_{11}$ parameter is a measure of reflected power when port is feed. Ideally the return loss must be as low as possible. For commercial antenna applications return loss of $-10 \mathrm{~dB}$ is acceptable. For antenna Characteristics $S_{11}$ provides return loss for input port

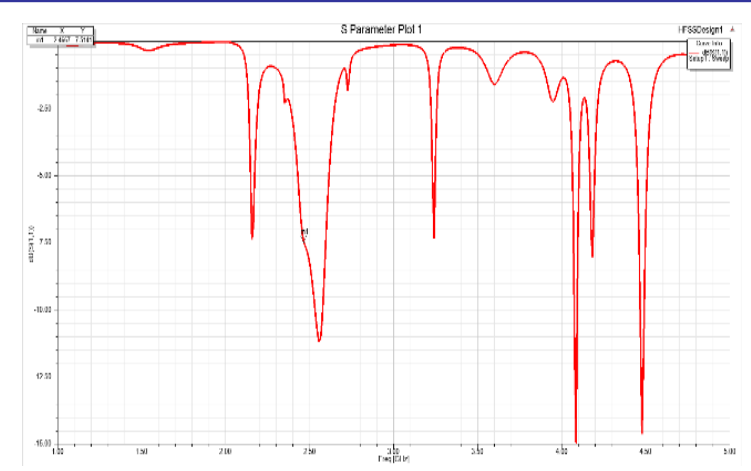

Fig. 6. Return Loss of Eight Element Array

\section{B. Radiation Pattern:}

Radiation pattern is plot of radiated power density to angle. The radiation pattern is a $3 \mathrm{D}$ plot or $2 \mathrm{D}$ plot. i.e, $P_{\text {rad }} V s \theta$,or $P_{\text {rad }} \operatorname{Vs} \varphi$

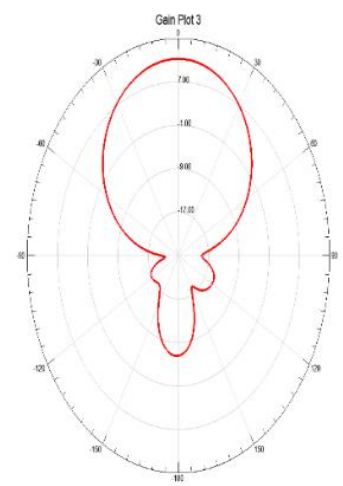

Fig.6(a)

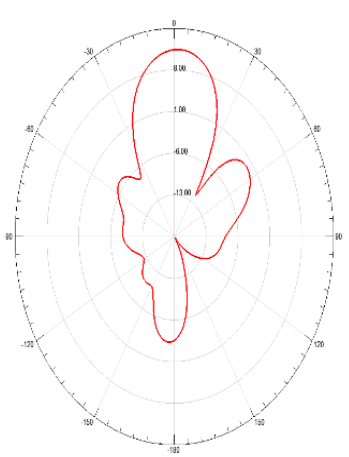

Fig.6 (b)

Fig. 6. Radiation Pattern of a) Single Element b) Eight Element array

\section{Gain:}

Gain is the ratio of the radiation intensity, in a given direction, to the radiation intensity that would be obtained if the power accepted by the antenna were radiation isotopically. If the efficiency is not 100 percent, the gain is less than the directivity. The single and eight elements array has a gain of $-6 \mathrm{~dB}$ and $11 \mathrm{~dB}$ at a resonant frequency range of $2.4 \mathrm{GHz}$. 
Gain Plot 1

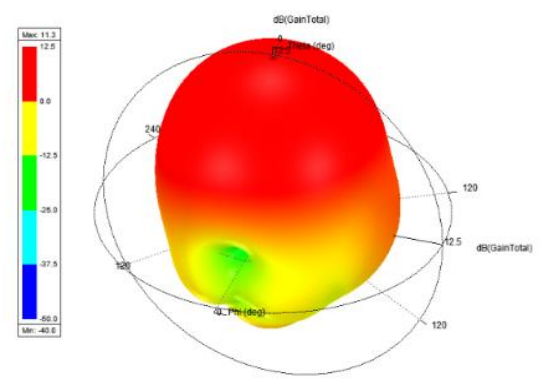

Fig 7. (a)

Gain Plot 1

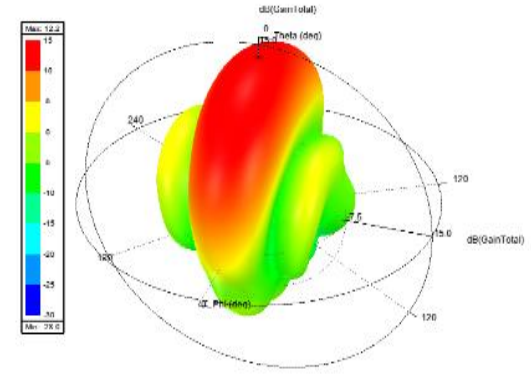

Fig 7. (b)

Fig.7. Gain of Single Element b) Eight Element array

\section{VSWR:}

Ideally, the VSWR value should be 1.54. Practically, the value of VSWR should be $<2$ is acceptable. The microstrip patch antenna while simulated in frequency range of $1-10 \mathrm{GHz}$, provides VSWR less than 2 at resonant frequency of $2.46 \mathrm{GHz}$. The VSWR response for four elements antenna array is shown in figure 8.

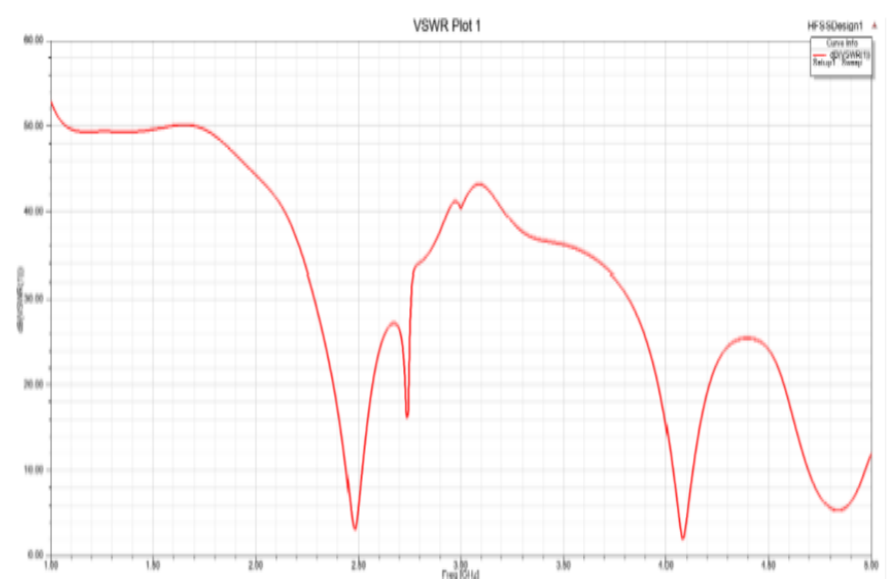

Fig.8. VSWR plot of Four Elements Antenna
TABLE 2 ARRAY PERFORMANCE

\begin{tabular}{|l|c|c|c|}
\hline Parameters & $\begin{array}{c}\text { Single } \\
\text { Element }\end{array}$ & $\begin{array}{c}\text { Four } \\
\text { Element } \\
\text { Array }\end{array}$ & $\begin{array}{c}\text { Eight } \\
\text { Element } \\
\text { Array }\end{array}$ \\
\hline $\begin{array}{l}\text { Radiating } \\
\text { Frequency }\end{array}$ & $2.4 \mathrm{GHz}$ & $2.4 \mathrm{GHz}$ & $2.4 \mathrm{GHz}$ \\
\hline Return Loss & $-26.8 \mathrm{~dB}$ & $-10.45 \mathrm{~dB}$ & $-10.25 \mathrm{~dB}$ \\
\hline $\begin{array}{l}\text { Input } \\
\text { Impedance }\end{array}$ & $53.4+\mathrm{j} 0.8$ & $50.2+\mathrm{j} 54$ & $49.2+\mathrm{j} 51$ \\
\hline Max. Gain & $5.2 \mathrm{dBi}$ & $11.3 \mathrm{dBi}$ & $12.3 \mathrm{dBi}$ \\
\hline Bandwidth & $26 \mathrm{MHz}$ & $42 \mathrm{MHz}$ & $48 \mathrm{MHz}$ \\
\hline
\end{tabular}

\section{REFERENCES}

[1] K. Yun, J. Gil, J. Kim, H. Kim, K. Kim, D. Park, J. Kwak, H. Shin, K Lee, J. Kwak, E. Yoon, A miniaturized low power wireless remote environmental monitoring system using microfabricated electrochemical sensing electrodes, TRANSDUCERS, Solid-State Sensors, Actuators and Microsystems, 12th International Conference on, 2003, vol.2, no., pp. 18671870 vol.2, 8-12 June 2003.

[2] A.C.Patel, M.P. Vaghela, H. Bajwa, P.K. Patra, Power Harvesting for Low Power Wireless Sensor Network. In Proceedings of the Antennas and Propagation Conference, Loughborough, UK, 16-17 November 2009; pp. 633-636.

[3] W. Zhao, K. Choi, S. Bauman, T. Salter, D.A. Lowy, M. Peckerar, M.K. Khandani, An Energy Harvesting System Surveyed for a Variety of Unattended Electronic Applications. Solid-State Electron. 2013, 79, 233 237.

[4] J.Masuch, M. Delgado-Restituto, D. Milosevic, P. Baltus, Co-Integration of an RF Energy Harvester into a $2.4 \mathrm{GHz}$ Transceiver. IEEE J. SolidState Circuits 2013, 48, 1565-1574.

[5] H. Nishimoto, Y. Kawahara, T. Asami, Prototype Implementation of Ambient RF Energy Harvesting Wireless Sensor Networks, IEEE SENSORS Conference, pp 1282- 1287, 2010.

[6] D.M. Pozar, Microstrip Antennas, Proc. IEEE, Vol. 80, pp.7981, January 1992.

[7] C.A. Balanis, Antenna Theory, John Wiley and Sons, Inc., 1997.

[8] V. Kushwah, G. Tomar, Size reduction of Microstrip Patch Antenna using Defected Microstrip Structures, InternationalConferenceonCommunicationSystemsandNetworkTechnolo gies, 2011.

[9] Chuck Fung, Basic Antenna Theory and Application, Springer, Worcester polytechnic institute, 2011.

[10] Online,https://www.rogerscorp.com/documents/606/acs/RTduroid-58705880-Data-Sheet.pdf,10th of January 2017.

[11] C. A. Balanis, Antenna theory analysis, and design, volume 3, John Wiley and Sons, Hoboken, New Jersey, 2005.

[12] N. Rao and D.V. Kumar, Gain and Bandwidth Enhancement of a Microstrip Antenna Using Partial Substrate Removal in Multiple-layer Dielectric Substrate, Progress in Electromagnetics Research Symposium Proceedings, Suzhou, China, pp 12851289, Sept. 12-16, 2011.

[13] R.A. Pandhare, P.L. Zade, M.P. Abegaonkar, Miniaturized microstrip antenna array using a defected ground structure with enhanced performance, Engineering Science and Technology, vol.19, 1360-1367, 2016.

[14] Y. Qian, D. Sievenpiper, A Novel Approach for Gain Bandwidth Enhancement of Patch Antennas, RAWCONN 98. 